\title{
Personal knowledge management: the foundation of organisational knowledge management
}

\author{
Priti Jain ${ }^{\prime}$ \\ Department of Library and Information Studies, University of Botswana \\ jainp@mopipi.ub.bw
}

Received: 17 December 2010

Accepted: 10 April 2011

\begin{abstract}
The purpose of this small-scale study was to explore how people perceived Personal Knowledge Management (PKM), whether people were aware of the PKM concept, and how PKM can have an impact on organisational knowledge management and productivity. A questionnaire survey with quantitative and qualitative questions was used. The study revealed that a majority (6־\%) of respondents were not aware of the PKM concept; $\square \%$ were aware, while $2 \%$ had a vague idea about it. Eighty three (8 $5 \%)$ felt that it was important to manage personal knowledge and that PKM could increase individual productivity and organisational performance. The major recommendations included creating awareness about PKM. It should be at the heart of each employee-development programme, alignment of personal and organisational goals and adequate facilities and training in PKM.
\end{abstract}

Keywords: Organisational knowledge management; personal knowledge management; individual productivity; organisational productivity.

\section{Introduction}

Increasingly, organisations depend on the contributions of knowledge workers. Knowledge workers are people with high levels of expertise, education and experience, whose primary role involves the creation, distribution or application of knowledge (Wright 2007). In this knowledge era all types of organisations are struggling to manage the collective knowledge they produce and use it to improve productivity and performance within the organisation. There is a close correlation between personal knowledge management and organisational knowledge management. If individuals become productive by managing personal knowledge, the organisation becomes productive. Personal knowledge management (PKM) is "an approach that complements organisational KM by focusing on ways to support productivity of an individual knowledge worker" (Efimova 2006). PKM is a tool which can equip knowledge workers with the necessary skills to manage their individual knowledge. In the world of the modern knowledge worker, it has become necessary for individuals to maintain, develop, and market their skills to give them any chance of a competitive advantage in the job market in both the short and long term (Pauleen 2009:222). Pauleen raised the question of how individual and organisational knowledge goals can be harmonised. This question was a further motivation for the author to explore the PKM issues; hence this study was carried out amongst knowledge workers at the University of Botswana in July 2010.

Indeed, most organisations stand by the stock statement that "our people are our greatest asset", but in practice they remain unreceptive to concepts such as PKM. Much of knowledge management research and practice is focused at the organisational level, aiming to develop an environment where knowledge is created, shared and used, as well as implementing specific interventions that support these processes (Efimova 2006). PKM seems to be a neglected area. Only few organisations equip employees with the appropriate tools and techniques to support their personal knowledge and information management needs (InsideKnowledge 2004). In this knowledge based economy, where knowledge plays a central role in economic prosperity, organisations are faced with tremendous challenges of improving individual capability and productivity. An important strategy for any organisation in this competitive age is to remain knowledgeable in the areas critical to the company's survival as well as those areas that will add to its ability to thrive (Blair 2006). Knowledge management has been seen as a strategic tool to manage employees' knowledge, but PKM as such does not get much attention, which is surprising given the fact that personnel are the most critical assets of an organisation. Personal success is the foundation of organisational success but often personal issues are linked to reduced productivity at work. The purpose of this study was to explore how people perceived Personal Knowledge Management (PKM); whether people were aware of the concept or not; how PKM can have an impact on organisational knowledge management and productivity. This study was also an attempt to explore how personal and organisational goals can be harmonised.

I. Dr. Priti Jain (PhD) is a Senior Lecturer in the Department of Library and Information Studies at the University of Botswana, Gaborone, Botswana. 


\section{Background to PKM}

The origin of personal knowledge management can be traced back as far as 1968, when Drucker (1968) used the term mentioning the dynamics of "knowledge work" and "knowledge workers". Drucker (200I) again used the phrases "knowledge worker" and "advanced knowledge workers" in 1974 to refer to knowledge professionals and also mentioned "personnel management". However, the term "personal knowledge" was first used by Polanyi (1958) and the term "personal knowledge management" (PKM) as such appeared for the first time in a working paper by Frand \& Hixon (1999). "It's been in the background since the early days of knowledge management, but the connection between personal and organisational effectiveness has so far been ignored” (David Skyrme Associates 2004). However, in the past two years people have begun to recognise the importance of PKM and there are several activities around PKM: blogs, workshops, conferences, e-book and online surveys. All of these are indications of growing awareness and recognition of PKM.

The PKM has multidisciplinary roots. One of the more apparent antecedents of PKM is Personal Information Management (PIM), which comes from research in library and information management as well as personal productivity tools and softwares (Jones \& Teevan 2007). The modern PKM focuses on how individuals can become productive knowledge workers.

\section{Literature review}

This section reviews some literature on personal knowledge management.

3.1 What is personal knowledge management (PKM)?

According to Martin (2006) personal knowledge includes knowledge gained from formal and informal instruction, memories, stories, personal contacts and relationships, books read or written, notes, documents, and photographs of us or by us. PKM has different descriptions: people-centred knowledge management (Gurteen 2009); a sub-set of organisational knowledge management; the starting point for KM; the 3rd KM (Anklam 2009); a bottom-up approach to knowledge management (Pollard 2008); human-centric KM (David Skyrme Associates 2004) and interpersonal knowledge management (Ash 2009). Thus PKM “is interpreted differently by different people” (Jones, Corner \& Hämäläinen, 2008).

PKM has been defined in different ways by various authors. The following table presents some definitions of PKM:

Table I PKM definitions

\begin{tabular}{|c|c|}
\hline Personal knowledge is & Source \\
\hline a system designed by individuals for their own personal use & Frand \& Hixon (1999). \\
\hline $\begin{array}{l}\text { managing and supporting personal knowledge and information to make it accessible, } \\
\text { meaningful and valuable to the individual; maintaining networks, contacts and communities; } \\
\text { making life easier and more enjoyable; and exploiting personal capital }\end{array}$ & Higgison (2004). \\
\hline $\begin{array}{l}\text { investigation of how knowledge workers can enhance their productivity by better encoding, } \\
\text { accessing, and reusing their personal knowledge }\end{array}$ & Volkel \& Abecker (2008:95). \\
\hline $\begin{array}{l}\text { knowing what knowledge we have and how we can organize it, mobilize it and use it to } \\
\text { accomplish our goals and how we can continue to create knowledge }\end{array}$ & Martin (2006). \\
\hline $\begin{array}{l}\text { to provide a framework for Individual Knowledge Workers to manage new information, } \\
\text { integrate it and enrich each individual knowledge database in an effective manner }\end{array}$ & Cheong \& Tsui (2010). \\
\hline $\begin{array}{l}\text { an overall structured process for intentionally managing information and turning it into useful } \\
\text { knowledge }\end{array}$ & Avery et al. (200I) cited in Cheong \& Tsui (20I0). \\
\hline $\begin{array}{l}\text { focused on personal productivity improvement for knowledge workers in their working } \\
\text { environments. }\end{array}$ & Academic Dictionaries \& Encyclopedias (20I0). \\
\hline
\end{tabular}

From the above definitions PKM can be distinguished with the following characteristics:

- It focuses on personal knowledge;

- It refers to knowledge which is important to an individual in personal, working and social capacities;

- It is the management of personal knowledge to make it easily accessible and usable;

- It is the foundation for organisational knowledge management;

- It emphasises the importance of PKM in order to improve organisational productivity; and,

- It is an ongoing activity.

In the context of this article, personal knowledge refers to knowledge which is already in a person's possession, and PKM means managing and maintaining that personal knowledge to enrich an individual knowledge database to retrieve 
knowledge time-effectively so as to use, re-use and mobilise it for the benefit of the person, the organisation and the community. Sometimes personal knowledge is narrowed down to tacit knowledge only. Here, it largely refers to explicit knowledge but also includes tacit knowledge.

\subsection{Why do we need PKM?}

A great deal of organisational knowledge resides in the individual employees' heads and individual knowledge databases. There is a scarcity of research in this area. Knowledge Management (KM) research emphasises extracting knowledge from people instead of encouraging them to manage their personal knowledge and link PKM to organisational knowledge management and productivity. Knowledge workers spend a lot of time looking for valuable information which is already in their possession. This lowers their productivity.

A survey conducted by Davenport (2003-2004) cited in Anklam (2009) found that an average user spent $40 \%$ of their time each day using technologies to process work-related information. According to a Workplace Productivity Survey commissioned by LexisNexis "sixty-two percent of professionals report that they spend a lot of time sifting through irrelevant information to find what they need; 68 percent wish they could spend less time organizing information and more time using the information that comes their way" (Business Wire 2008). These are indications of how personal knowledge, time management and productivity are tied up in PKM. Organisations need to realise that employees waste much of their time in tracing useful information. It would be better if PKM could lead to greater organisational success. According to Jefferson (2006), PKM was developed in response to the technology revolution which resulted in the problem of information overload. According to Verma (2009) it is a response to the idea that knowledge workers increasingly need to be responsible for their own growth and learning (Verma 2009). So, PKM is important for all people and organisations envisaging enhancing their productivity to keep abreast with the latest information literacy skills and compete in the global village. Available literature notes numerous benefits of PKM, which can be categorised into two types, individual benefits and organisational benefits:

Individual Benefits: PKM can provide the following benefits to an individual worker:

- PKM can address the information overload problem;

- Individuals can recognise their own value and consequently make better decisions for self-development;

- Individuals are better equipped to work and be more productive;

- PKM enables knowledge-based and informed decision making;

- Employees feel motivated if given PKM tools and methods to make their lives easier and them more employable;

- It makes people innovative and think critically;

- PKM identifies the personal knowledge and skill gaps and builds on capacities;

- PKM manages personal human capital for professional excellence (Mart \& Enache 2008; Cheong \& Tsui 20I0).

Organisational Benefits: PKM benefits to organisation are:

- Improved productivity and performance;

- Continuous innovation;

- Effective decision making;

- Internal knowledge dissemination; and,

- External information awareness.

Thus, PKM plays an important role in the KM process, both individual and organisational; PKM improves their competences. The roles of PKM are positively correlated to the values of PKM for individuals and organisations (Cheong \& Tsui 2010). PKM is managing key information/knowledge so that it can be easily accessible when needed.

\subsection{PKM and organisational performance}

The main drive behind PKM is to leverage a personal knowledge database and through it organisational knowledge and productivity. It has been empirically proved that there is a close relationship between personal knowledge and organisational knowledge management. Considering employees themselves as the means of tacit knowledge, Kiessling, Richey, Meng \& Dabic (2009) believe that the firm based knowledge management resulting from the employees knowledge leads to organisational outcomes such as product improvement, firm innovation, and employee improvement, and came up with a model that the authors refer to as a "conceptual model; a meso-level model of Eastern European knowledge management".

Most recently Cheong \& Tsui's (2010) study has established that PKM can benefit both individuals and organisations. Based on the research findings Cheong \& Tsui $(2010)$ have developed the first PKM model depicting the conceptual framework of PKM, which is leveraged on the Web 2.0 concepts. The model is dynamic, where personal information 
management; personal knowledge internalization, personal wisdom creation, and inter-personal knowledge transferring are the main components.

\subsection{PKM skills}

PKM skills are important. If knowledge is power, a precious asset to attain leadership and self-realisation, why should it not be at the centre of an individual's personal aspirations and efforts? Why should it not be the object of specific skill development? (Pettenati, Cigognini, \& Sorrentin 2007). Too often, knowledge management is thought to be contained in sophisticated electronic networking software tools and the human factor is ignored. PKM skills are far more important than technical tools (Richardson 200I). Avery et al. (200I) cited in Cheong and Tsui (20l0) identified seven skills in their proposed PKM framework for (I) retrieving information; (2) evaluating information; (3) organizing information; (4) collaborating around information; (5) analysing information; (6) presenting information; and (7) securing information.

Along the same line, Berth (2003) presented a 7-point PKM framework, which was developed by Prof. Paul Dorsey at Millikin University in Decatur. This is: I. accessing information and ideas; 2. evaluating information and ideas; 3. organizing information and ideas; 4. analyzing information and ideas; 5. conveying information and ideas; 6. collaborating around information and ideas; and 7. securing information and ideas. Undoubtedly, these are all important skills for PKM, but they basically focus on information without mention of knowledge. According to Lambe (2002), PKM skills are: identifying sources of knowledge, searching, navigating, analyzing, organizing, linking, mapping, converting back and forth between tacit (head) knowledge and explicit (written down) knowledge, relationship building skills, communication, presentation, knowledge packaging, and so on. Moving away from an individualistic approach, Lambe argues that each of us have different personalities and profiles in relation to our personal knowledge affinities and capabilities, so each of us can help others at the simplest working levels in different roles as a: collector, connector, consumer, critic, communicator and creator of personal knowledge depending on personal capabilities and limitations. In this way, the more we reinforce our role, the more value we can add in a knowledge-based team.

Academic Dictionaries and Encyclopedias (2010) indicate a number of skills, which are more contemporary and elaborate as follows:

- Reflection: Continuous improvement on how the individual operates;

- Manage learning: Manage how and when the individual learns;

- Information literacy: Understanding what information is important and how to find unknown information;

- Organisational skills: Personal librarianship? Personal categorization and taxonomies;

- Networking with others: Knowing what your network of people knows, who might have additional knowledge and resources to help you;

- Researching, canvassing, paying attention, interviewing and observational 'cultural anthropology' skills;

- Communication skills: Perception, intuition, expression, visualisation, and interpretation;

- Creative skills: Imagination, pattern recognition, appreciation, innovation, inference. Understanding complex adaptive systems; and,

- Collaboration skills: Coordination, synchronisation, experimentation, cooperation, and design.

Thus, the major PKM skills can be characterised as:

- Life-Long Learning skills;

- Manage learning skills;

- Information literacy skills;

- Organisational skills;

- Networking and collaborative skills;

- Research and observation skills;

- Communication \& visualisation skills;

- Creative and innovative skills;

- Latest information and communication technology skills; and,

- Information management skills.

\subsection{PKM adoption stages}

According to an exploratory study carried out on $206 \mathrm{KM}$ participants in 44 different countries/locations by Cheong \& Tsui (2010) only 37\% respondents had attended PKM training. The two authors elaborated the respondents' stage of PKM adoption in five stages: knowledge stage, persuasion stage, decision stage, implementation stage and confirmation stage. Cheong \& Tsui (2010) interpreted the five adoption stages as below:

- Knowledge stage, where the individual is exposed to PKM and knows little about it but has not been inspired to find more information about PKM. 
- Persuasion stage, at this stage the individual is interested in PKM and actively seeks information about it.

- Decision stage, when the individual takes the concept of PKM and makes a decision to adopt or reject it.

- Implementation stage, at this stage the individual uses PKM and may explore it further.

- Confirmation stage: the individual continues using it and may use PKM to its fullest potential (Cheong \& Tsui 20I0).

3.6 Tools and technologies to manage personal knowledge

There are several tools and technologies to manage personal knowledge. Some of them are as follows:

- SasS Applications: Software-as-a-Service (SaaS) is a computer application over the Internet via a Web Browser. Today there are many SaaS applications available that can be used by students to support their PKM. There are also cloud based SaaS applications. To organise information there are online notebooks such as ZOHO. Introduced in 2005 $\mathrm{ZOHO}$. ZOHO provides a wide range of online applications including an eNotebook, which collects information into tabbed sections, or pages. Any page in the notebook can contain a collection of media types such as text, images, video, and links as objects on a page.

To analyse and collaborate around information, there is Google Docs that provides word processing, spreadsheet, presentation and drawing and diagrams tools and easy to create HTML forms. To present Information, Google Docs has presentation software such as PowerPoint and presentations can be shared. There is also a site called SlideShare. This site is the equivalent of YouTube for slide presentations (Google Docs 2010; Garner 2010; SaaS 2010; ZOHO 20I0).

- PpcSoft iKnow 2010 for Windows: PpcSoft iKnow is a personal knowledge management tool for helping you store and find the information when you need it. Especially designed to handle a large number of notes PpcSoft iKnow helps you manage information overload, saves time and improves productivity. It consists of inter-linked notes (where each note is like a simple web page or yellow note) that gives you access to your information. It collects all kinds of information into PpcSoft iKnow, and creates your own, personal knowledge web on your computer. It has several features; such as, collect information, Connect notes, Quick search, auto complete. (PpcSoft 20I I). Other PKM Softwares are E-mail, Calendar, Task managers, Weblogs (with a Web RSS feed), Online Web Assistants, Wiki, Personal Wiki, and Semantic Wiki (Garner 20I0).

Based on the above literature review, the basics of PKM can be summarised in Figure I consisting of PKM Skills, PKM benefits for individual and organisation, PKM and organisational performance, PKM adoption stages and PKM tools \& technologies:

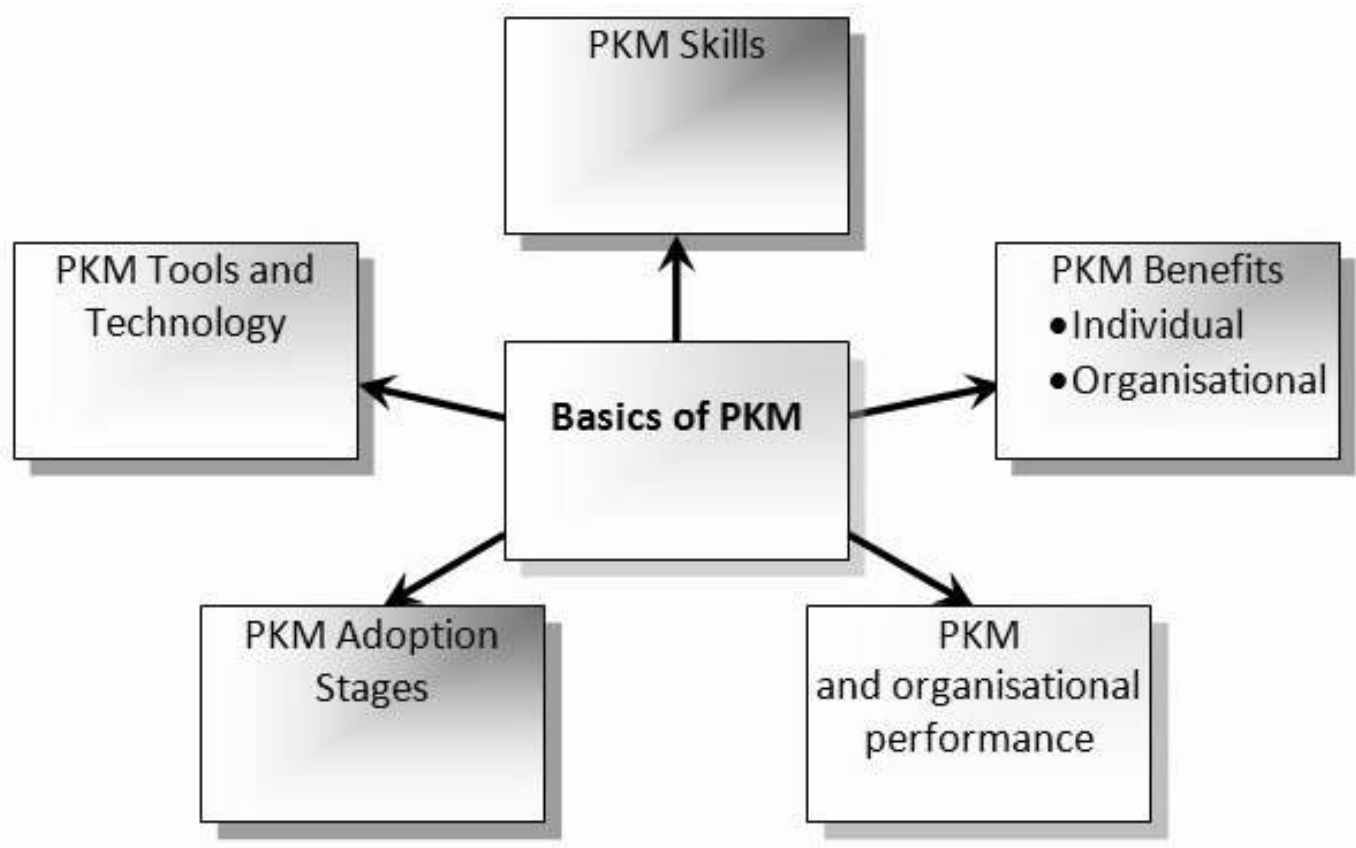

Figure 1 Basics of PKM

\section{Research finding and data analysis}

This study was undertaken to explore the PKM status in the Faculty of Humanities at the University of Botswana in July 2010. 


\subsection{Scope and context of the study}

The University of Botswana has 6 faculties; this study was carried out in the Faculty of Humanities. The Faculty of Humanities was chosen because it is one of the largest faculties at the University of Botswana and most of the research in the Faculty involves searching and researching for knowledge and information from diverse sources. Owing to the above facts, the Faculty of Humanities was the most appropriate for the subject, so the research was carried out. Although the study was limited to the Faculty of Humanities, it might generate interest in extending the study to other faculties. The Faculty of Humanities comprises the following seven departments: African Languages and Literature with 12 staff members, English 31, French 5, History 13, Library \& Information Studies 15, Media Studies 8 and Theology \& Religious Studies 14, resulting in an overall total of 98 staff members.

This was an exploratory study. The purpose of this study was to explore how people perceived Personal Knowledge Management (PKM) with major questions whether respondents were aware of the concept of PKM or not; whether the harmonisation of personal and organisational knowledge goals was possible; how PKM can have an impact on organisational knowledge management and productivity. The study also aimed to create awareness of concept of PKM,

\subsection{Methodology}

A structured questionnaire was used to carry out the study, including both quantitative and qualitative questions. Reasons for employing this approach were to ensure reliability, time effectiveness and mutual inclusiveness. The questionnaire designed for this study had 18 questions. Out of the 18 questions, 15 were quantitative where respondents were provided with options to tick the right answers. Each quantitative question had "Any other" option to allow the respondents to write what was not in structured options. In some questions respondents were allowed to choose more than one option.

Qualitative questions were only 3. One question asked the respondents if they were aware of the concept of PKM; how they would define it. This was to enable respondents to define PKM as they understood it. In the second qualitative question respondents were asked if it was possible to harmonise personal and organisational goals and what their suggestions for harmonisation were. The last qualitative question was for additional suggestions or comments, which gave the respondents another opportunity to suggest or comment on the pertinent issues which the researcher might have excluded from the survey. These qualitative questions provided respondents with ample opportunities to express their points of view on harmonisation, and providing options could limit them. Sixty (60) questionnaires were delivered, of which 54 were responded to at the response rate of $90 \%$. Of 54 responded questionnaires $34(63 \%)$ were sent and responded to electrically, while 20 (37\%) were self-administered and collected.

The purpose of any sampling is to represent the characteristics of the entire population. In this study no sampling technique was used because the aim of the study was to involve all teaching staff in the Faculty of Humanities who was there and willing to participate.

Data analysis was done by simple frequency count and cross tabulation, comparing responses across demographic variables. The qualitative (open-ended) questions were analysed separately, by identifying and grouping key responses into themes, after which related/associated themes were further grouped into variables for frequency count.

\subsection{Findings}

At the end of the academic year some staff members go on vacation. Of the 98 staff members, 60 staff were available and 54 (90\%) participated in the survey. Table 2 displays the respondents:

Table 2 Respondents' profile $(\mathrm{N}=54)$

\begin{tabular}{|l|l|l|}
\hline Respondents & Number & $\%$ \\
\hline Professors & 4 & 7 \\
\hline Associate professors & 8 & 15 \\
\hline Senior lecturers & 22 & $4 \mathrm{I}$ \\
\hline Lecturers & 20 & 37 \\
\hline Total & 54 & 100 \\
\hline
\end{tabular}

As evident from the above table, among the respondents the majority ( $41 \%)$ were senior lecturers. For the purpose of easy reading, all the percentages throughout the paper are rounded up. 
Respondents were asked several questions. On the question whether they were aware of the concept of PKM or not, $63 \%$ indicated that they were not aware, $35 \%$ were aware, while $2 \%$ had a vague idea about it. Table 3 presents the responses from those, who knew about the concept of PKM:

Table 3 PKM defined by the respondents $(N=54)$

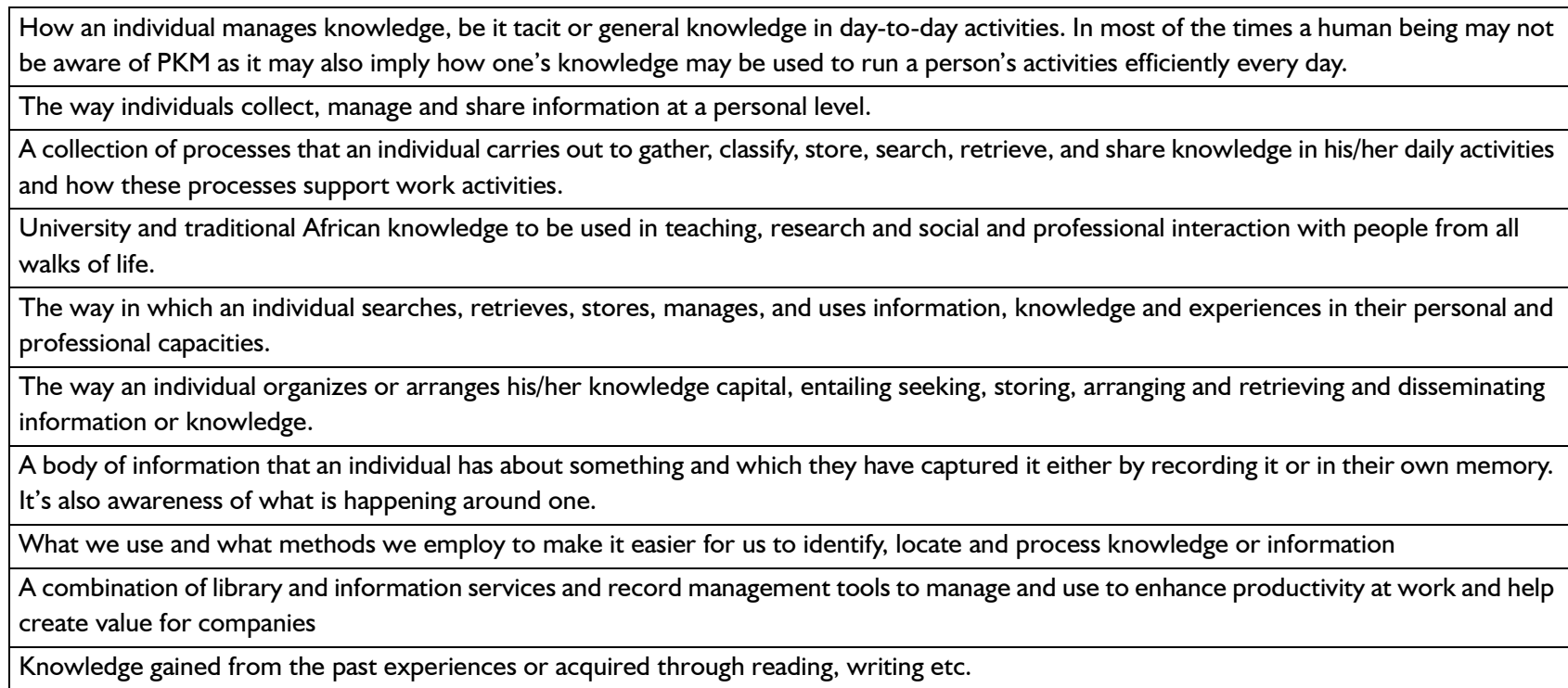

The above selection of definitions from the respondents shows that some respondents were really familiar with the concept of PKM but the majority were not.

On the importance of personal knowledge, $83 \%$ (45) felt that it was important, 13\% (7) thought it was not important, while $4 \%$ (7) were not sure. The reasons of PKM importance were given as shown in Table 4:

Table 4 Why PKM is important

\begin{tabular}{|l|l|l|}
\hline PKM importance & Number & $\%$ \\
\hline It can improve organisational performance & 45 & 83 \\
\hline It can increase individual productivity & 43 & 78 \\
\hline It identifies the personal knowledge gaps & 38 & 70 \\
\hline It can solve information overload problem & 37 & 66 \\
\hline It enhances knowledge-based decision making & 33 & 61 \\
\hline
\end{tabular}

Here it is important to note that even though respondents were not aware of PKM, still they were able to appreciate its importance. Secondly, they seemed to practice PKM without knowing about it.

On the question of what type of knowledge was important to the respondents, the responses are presented in the Table 5:

Table 5 Type of personal knowledge (PK) important to respondents

\begin{tabular}{|l|l|l|}
\hline Type of PK & Number & $\%$ \\
\hline Work-related documents & 54 & 100 \\
\hline Personal library & 39 & 72 \\
\hline Contacts and community networks & 37 & 69 \\
\hline Lecture notes & 34 & 63 \\
\hline E-mails & 32 & 59 \\
\hline
\end{tabular}

Note: Here a person could choose more than one option.

Work-related documents were perceived as crucial by everyone, but lecture notes were perceived important by $63 \%$, that seems to suggest that other respondents might have considered lecture notes as part of work-related knowledge. It is evident from this study that personal libraries are considered an important type of personal knowledge. Indeed, a well- 
managed personal library brings several benefits with it: source of recreation and relaxation, a valuable source of teaching material, facilitates social networking carrying knowledge from one person to another. Identifying contacts and community networks as an important type of personal knowledge means people appreciated the significance of social networking. It is through social networking people are able to share and exchange expertise, collaborate, help each other and improve each others' skills and knowledge. Due to technological advancements relations and networks have become even more critical than ever before. At the press of the button one can be face-to-face and share and exchange information and knowledge. A substantial number of people acknowledged that e-mails were one of the important types of personal knowledge, yet many highlighted that it was challenging to organise e-mails and retrieve them when needed.

The respondents were further asked how much time they spent in searching for the relevant information; Figure 2 reflects the responses:

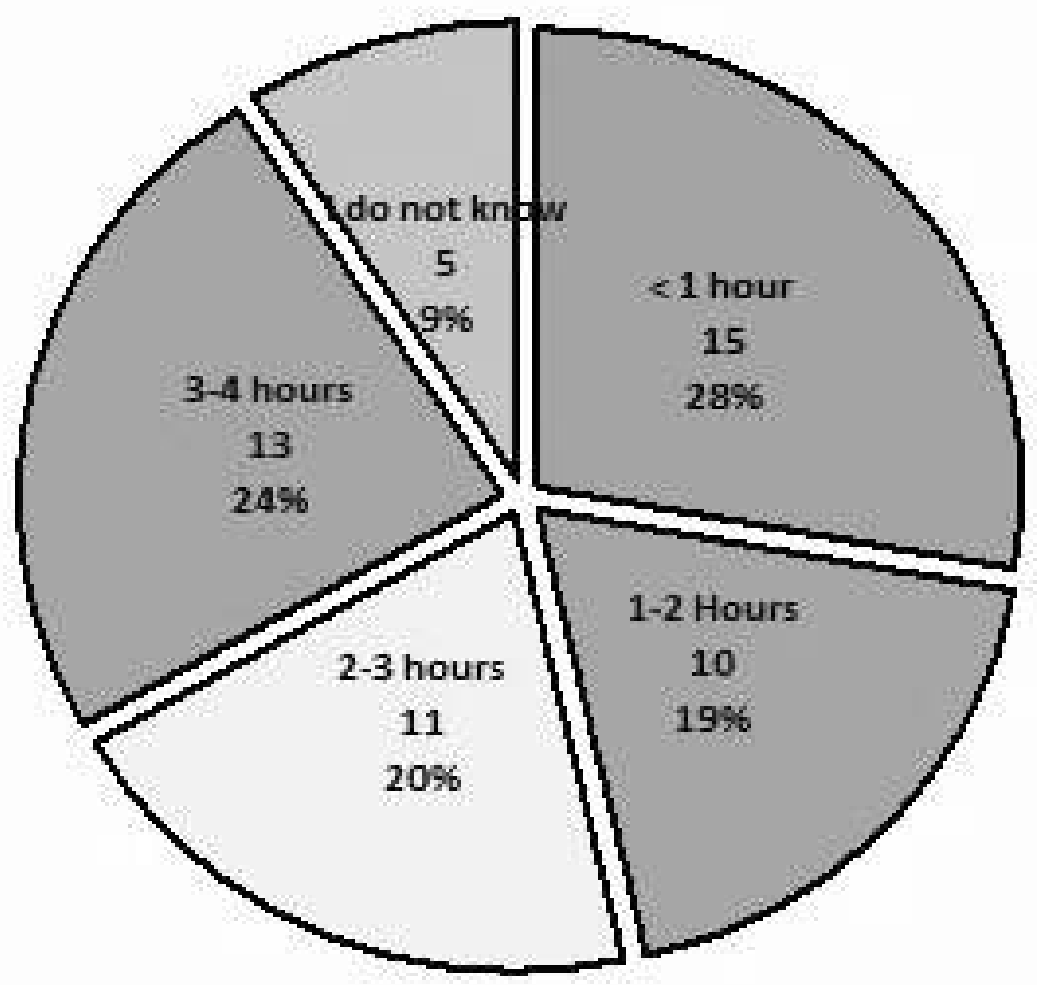

Figure 2 Time spent searching for relevant information per day No: 54

According to the above Figure 2, the respondents spent an average I hour 46 minutes per day in looking for the relevant information, which translates to 9 hours 40 minutes per week and is equivalent to one working day. It would mean employees are working equivalent to 4 days a week instead of 5 . This illustrates the need for PKMand document management. Each of us has an incredible knowledge base, but we do not use all of it regularly because we do not know where the volumes, chapters and margin notes are (Martin 2006). Due to the information explosion in this digital age, document management is a serious problem in most organisations today; therefore organisations are incessantly looking for new strategies to make their people more productive and efficient. Document management software has become an intrinsic part of most organisations and there are several document management software and systems available in the market to manage, create, store, categorise and retrieve vast quantities of data and knowledge, such as, content Central, SharePoint Server, Knowledge Tree Document Management, Document Locator by ColubiaSoft, OpenDocMan. Organisations need to avail and train staff in the latest technologies to manage their knowledge. If all employees manage their knowledge effectively and efficiently, they would not be wasting their time in looking for the relevant information. These findings corroborate Davenport's (2003-2004) cited in Anklam (2009), that employees spent 40\% of their time each day using technologies to process work-related information.

In the current study on not finding the right information, $69 \%$ were frustrated and disappointed, $31 \%$ felt unproductive. By practising PKM and time management techniques the wastage of time could be utilised to realise personal and organisational goals. If all staff members manage work-related knowledge properly, this would have a direct 
bearing on organisational productivity and performance. It is therefore important for people to manage personal knowledge.

There is also a need to make staff members aware of their potential and personal knowledge databases and skills in order to motivate staff to utilise their skills to their optimum potential. Once individual workers become willing to utilise their skills in a way that benefits both them and their organisations in service of others and for improving group knowledge, they plan to manage their personal knowledge accordingly (Avery et al. 2003) cited in Jones, Corner and Hämäläinen (2008). Therefore, respondents were further questioned how often they updated their personal knowledge database. Table 6 displays the results.

Table 6 Update of personal knowledge database $(\mathrm{N}=54)$

\begin{tabular}{|l|l|l|}
\hline Update of personal knowledge & Number & $\%$ \\
\hline Every day & 14 & 26 \\
\hline Every week & 14 & 26 \\
\hline Every month & 13 & 24 \\
\hline Every six month & 8 & 15 \\
\hline Did not know & 5 & 9 \\
\hline Total & 54 & 100 \\
\hline
\end{tabular}

As evident from the findings above, only $26 \%$ of the respondents were able to update their personal knowledge database every day. To ascertain the challenges and limitations associated with updating personal knowledge database, respondents were further asked if they faced any challenges in managing personal knowledge. Of the 54 respondents, $55 \%$ indicated that they faced challenges and $45 \%$ not. The major challenges were identified as shown in Table 7 :

Table 7 Challenges in managing PKM

\begin{tabular}{|l|l|l|}
\hline Challenges & Number & $\%$ \\
\hline Lack of facilities & 36 & 67 \\
\hline Lack of time & 34 & 63 \\
\hline Lack of awareness of PKM tools \& technology & 38 & 54 \\
\hline Lack of time management skills & 28 & 52 \\
\hline
\end{tabular}

Note: Here a person could choose more than one option.

As apparent from the above Table, the lack of facilities was identified as most challenging by 36 (67\%) respondents. Indeed people cannot perform to their optimum potential if they are not well-equipped with adequate facilities including new technology. Lack of time was another challenge. For a lack of time, one respondent commented, "Never enough time prioritized to do things". Another respondent observed, "There is just no time to even think that I need to manage my personal knowledge. As a lecturer, I find myself in a hurry to publish and advance my career. The need for PKM only rings in my mind when I am looking for something and I cannot find it". On a similar note two respondents noted, "The workload at the University gives little chance to manage any PK”.

These findings suggest the need for well-balanced job responsibilities and a well-planned working schedule and time management skills. As Jefferson (2006:37) has rightly stated, "In order to combat the barrage of information encountered during a typical workday, individuals require PKMs". The respondents were also asked to make suggestion to overcome the challenges and they suggested the following ways:

Table 8 Suggestions to overcome challenges

\begin{tabular}{|l|l|l|}
\hline Suggestions to overcome challenges & Number & $\%$ \\
\hline By knowing more about personal knowledge management & 40 & 74 \\
\hline Training in personal knowledge management & 36 & 67 \\
\hline Availability of modern ICT facilities & 33 & $6 I$ \\
\hline Training in time management & 3 I & 57 \\
\hline I do not think it is important & 4 & 7 \\
\hline
\end{tabular}

Note: Here a person could choose more than one option. 
To pursue the PKM issue further in relation to organisational productivity, the respondents were asked whether personal knowledge and organisational knowledge can be harmonised, $85 \%$ respondents were in the agreement that it was possible to harmonise and I5\% said no. Table 9 displays the suggestions recommended by the respondents to harmonise the personal and organisational goals:

Table 9 Suggestions on harmonisation of personal and organisational goals

\begin{tabular}{|l|l|l|}
\hline Suggestions & Number & $\%$ \\
\hline PKM should be at the heart of each employee development initiative & 45 & 83 \\
\hline Alignment of personal \& organisational goals & 40 & 74 \\
\hline Incentives to extraordinary performers & 30 & 56 \\
\hline Organisations be more responsive to employees' individual needs and priorities & 28 & 52 \\
\hline
\end{tabular}

Note: Here a person could choose more than one option.

It is evident from the above table, the majority of $83 \%$ respondents suggested that the PKM should be at the heart of each employee's development initiative in an organisation.

Based on the findings, literature review, and author's own understanding, the Figures 3 shows how personal knowledge management can be implemented in an organisation.

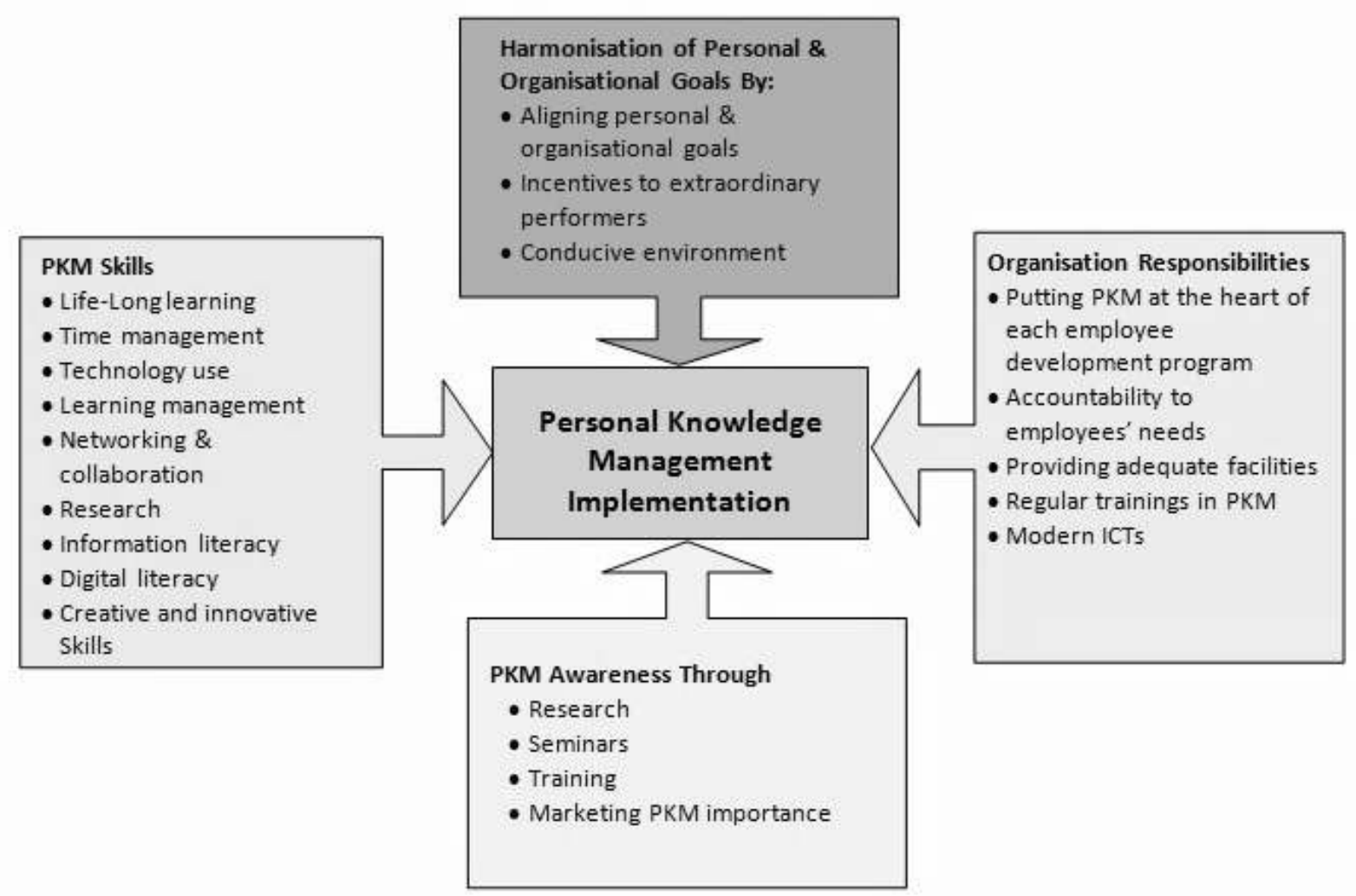

Figure 3 PKM implementation

\section{Discussion of implementation and major findings}

This section discusses the implementation and major findings:

\subsection{PKM skills and training}

Training in PKM was recognised as another way to harmonise organisational and personal goals by $67 \%$ respondents. Indeed by addressing basic productivity related problems such as training and incentives, PKM employees could have 
more time for higher value work. As most of the respondents (96\%) had pointed out, if they did not find relevant information, they felt frustrated, disappointed and unproductive. It becomes more critical to manage personal knowledge in knowledge-intensive institutions such as universities, where the main activities are research, teaching and learning. PKM provides the individual with the tools and techniques they need to surmount the overwhelming information they encounter at the work place and to enable them to increase their productivity (Jefferson 2006). There is a co-relationship between personal capacity building and organisational capacity building. If the employees are not skilled in PKM, it would have a negative impact on organisational knowledge management.

Therefore, there is a need of adequate trainings to equip all staff members with all the modern techniques and skills to manage and maintain personal knowledge, such as, life-long learning, time management, technology use, leaning management, networking and collaboration, research, information and digital literacy skills.

\subsection{Time management}

Time management is seen as another important dimension of personal knowledge management in this study, as $57 \%$ of respondents suggested that training in time management was necessary to overcome the challenges of PKM. Time management is the art of arranging, organising, scheduling, and budgeting one's time for the purpose of generating more effective work and productivity (Estes 20l0). It is a set of principles, practices, skills, tools, and systems working together to help you get more value out of your time with the aim of improving the quality of your life (Constandse 2007). The typical management problems in PKM are related to time and task management, matching work habits with personal productivity level variations, investing time into personal learning and PKM improvements and work-life balance (Wales 2010). Indeed in this $24 / 7$ busy world, time management is crucial for all of us. It is important therefore to equip staff members with time-management skills in order to improve personal productivity leading to organisational productivity. Improving your time management skills can even help you get better results by doing less work, because you're focusing on the things that really matter rather than all the low-priority busywork that just keeps you busy (Constandse 2007). There are numerous effective time management software such as, Effexis Software, Time management software system, To-Do List Software, Daily planner.

\subsection{Harmonisation of personal and organisational goals}

The majority of $85 \%$ of respondents mentioned that the harmonisation of personal and organisational goals was possible. Eighty three (83\%) respondents suggested that harmonisation of personal and organisational goals was possible by putting PKM at the heart of all employee development programs and $74 \%$ said harmonisation was possible by alignment between personal and organisational goals. To align personal and organisational goals, there is a need for understanding what organisational expectations are from the staff and what do staff expect from the organisations and then formulate personal goals to implement organisational goals. It is important to look at oneself as part of an organisation, the two cannot be separated. Knowing organisational goals enables one to initiate activities that would contribute to the achievement of the organisational goals. This can be done by regular discussions, workshops and seminars on what the organisation's objectives are and how individuals working for the organisation can dovetail their personal goals with those of the organisation. Following these suggestions, PKM can contribute greatly to organisational knowledge management, performance, and productivity as the application of personal knowledge leads to the achievement of organisational goals.

It is evident from the survey that harmonisation between the organisational and personal goal is a two-way process. As much as an organisation expects employees to align their goals with organisational goals, employees also have expectations from their organisations. One respondent observed, "There should be clear and specific objectives for personal and organisational goals. They should not be mixed up". Yet another respondent mentioned, "Mostly initiatives from the organisation's side should show the relevance and role of organisational objectives for individuals to their employees". Hence, there is a need for "systems with the capability to adapt to individual styles and work methods while imposing the structure necessary to facilitate accurate retrieval and application of existing knowledge" (Jefferson 2006:37). By valuing personal goals and investing in PKM, organisations can transform their performance and productivity. So there is a need for alignment of personal goals, incentives to extraordinary performers and a conducive working environment.

\subsection{Incentives}

Incentives for extraordinary performers was suggested by $56 \%$ respondents as means to harmonise personal and organisational goals. Incentives are often a financial type of motivation offered by the organisation to the employee if he/ she achieves the set target in time. They have been recognised throughout history as the best way to manage and motivate employees' performance. Many big companies around the world are successful because of proper employee incentive plans. If organisations cannot control individual members' initiative or desire, they can at least provide an environment that fosters learning and personal development (Jones, Corner \& Hämäläinen 2008). By introducing better 
remuneration, rewards and recognition systems, employees can be motivated to align their individual goals to organisational goals. As one respondent commented, "harmonisation of personal and organisational goals is possible through better remuneration, rewards, recognition, appreciation from the institution, improved working conditions in which employees feel worthwhile as engines of the institution's programmes". Another respondent observed, "An organisation should be in a position to accept and uplift those individuals who go beyond the organisational goals but remained linked with the organisation".

All this suggests that like any other initiative there is a need for adequate incentives to make PKM a success. Knowledge management means asking people to devote their scarce time to codifying their newly acquired knowledge and transmitting it to others. People need to have personal and organisational incentives and they need to be able to access training to use new tools (Richardson 200I). This can be done by introducing a variety of incentives:

- By including PKM in job descriptions and performance evaluations;

- By providing bonuses to people who contribute the most useful information;

- "Reputational" incentives via a "best-seller" list that publicizes the most frequently accessed contributions to a knowledge database;

- Quantify and measure the success of a knowledge sharing program and then publicizes the results detailing which parts of the organisation have contributed to success (Richardson 200I).

\subsection{Organisational responsibility}

As discussed earlier, both employer and employees have to understand each-others' goals and expectations in order to align the two for a successful PKM implementation. "The personal side of KM is often neglected: interventions and systems are designed and implemented without thinking about how they would match the practices and daily routines of individual knowledge workers" (Efimova 2006). By incorporating individual styles and preferences into traditional KMs, organisational productivity can be improved without imposing additional effort from a worker's perspective (Jefferson 2006). Making organisations more responsive to employees' individual needs and priorities is essential. The only place where knowledge can be turned into action is at the individual level. Organisations need to create learning organisations down to the individual level (Blair 2006).

Rapidly changing new technology requires constant renewal of knowledge and lifelong learning. If employees are trained in PKM, it would automatically have a positive impact on organisational success. So, it is vital for all organisations to change their values and priorities according to the needs of the emerging knowledge economy and innovative working culture and accommodate the new working styles and needs of their employees in organisational culture. It is possible only when organisations can see the bigger picture of their employees' contributions and value their personal knowledge at the root and increase their footprints. All of this requires a cultural change in organisational behaviour. Organisations should put PKM at the heart of each employee development program, should feel accountable to employees needs and provide them with adequate facilities and training.

5.6 Availability of modern information and communication technology (ICT) facilities

The availability of modern ICT facilities was identified as another way to overcome PKM challenges by $61 \%$ respondents. Indeed in this digital age where every job is dependent on ICT facilities, it is not an option but a survival kit to have access to latest technologies to enable employees to work smartly, effectively and efficiently.

\subsection{Creating awareness of PKM}

It was encouraging to note that although PKM was a new phenomenon to the majority of the respondents, they were keen to know more about it. As shown in Table 8, a substantial number of respondents (74\%) emphasised that there was a need to create awareness of PKM so that more and more people start practising it in their daily activities. In this study survey a number of the respondents acknowledged that it was a very interesting study and they enjoyed filling in the questionnaire and learned of something new. For example, one recognised, "This research has opened my horizon on the importance of PKM". Some respondents stated that at the beginning they were not aware of the concept and towards the end of the questionnaire; they felt they were aware of it. Another few observed, "Having gone through the questionnaire, I now have an idea about PKM although I had indicated in the beginning of the questionnaire that I had no knowledge of the concept". Further, 83\% agreed that PKM should be at the heart of any employee-development plan and $69 \%$ felt that there was a need for constant renewal of individual knowledge. All of this shows people's interest in

PKM. Hence, there is a need to create PKM awareness through research, seminars and conferences, training and marketing PKM importance.

\section{Conclusion}

The purpose of the study was to explore whether respondents were aware of the concept of PKM or not; and, whether the harmonisation of personal and organisational knowledge goals was possible. The majority of staff were not aware of 
the concept, still amazingly they appreciated the concept and they were in consensus that harmonisation of personal and organisational goals is possible. In fact the results of the study seem to suggest that some respondents were practicing PKM unknowingly. The other aim of the study was to create awareness of the concept of PKM, this has been achieved by creating awareness of the concept of PKM among Faculty members.

From the research findings it is evident that PKM is a management tool to improve personal effectiveness, which has direct bearing on an organisation's improved effectiveness and productivity. The majority of the respondents were in the agreement that PKM should be at the heart of each organisational employee development program and there is a need to create awareness of PKM and availability of adequate infrastructure to introduce PKM successfully. Thus, PKM should be considered as the foundation of organisational knowledge management.

\section{Recommendations}

The article puts forward the following recommendations:

- Since the majority of the respondents were not aware of the concept of PKM, it is imperative to create awareness about PKM through seminars, workshops, trainings;

- To harmonise personal and organisational goals, it is the responsibility of the organisation to provide conducive environment by providing adequate trainings, incentives and all the necessary facilities;

- Universities/organisations knowledge systems should put PKM at the heart of any employee-development programme;

- Employees' individual preferences and working styles should be incorporated into corporate KM infrastructure;

- Universities/organisations should focus on the need to constantly renew staff knowledge to survive in persistently changing environments;

- Adequate incentives should be provided to encourage academia to adopt PKM fully and align their personal goals with organisational goals;

- There should be a proper training plan and facilities to equip staff with all the necessary skills to enable staff to practice PKM at its optimal potential;

- Staff should be regularly trained in using the latest information and communication technologies to manage and maintain personal knowledge; and

- To work smartly staff should be endowed with sufficient time-management skills and programs.

\section{References}

Academic Dictionaries \& Encyclopedias. 20I0. [Online]. http://en.academic.ru/dic.nsf/enwiki/495 449 . (Accessed on 21 November, 20I0).

Anklam, P. 2009. The 3rd KM: personal knowledge management. [Online]. http://www.theappgap.com/the- $\square r d-k m-p e r s o n a l-$ knowledge-management.html. (Accessed on 29 May, 2010).

Ash, J. 2009. People: Managing, not hoarding, personal knowledge. [Online]. http://www.smartpeoplemagazine.com/2009/I //kmsix-pack-5/. (Accessed on 22 May, 2010).

Berth, S. 2003. Personal Toolkit: a framework for personal knowledge management tools. [Online]. http://www.kmworld.com/ Articles/Editorial/Feature/Personal-toolkit-A-framework-for-personal-knowledge-management-tools-94l6.aspx. (Accessed on 23 May, 2010).

Blair, M. 2006. Personal knowledge management: an approach to understanding what you know and need to know through conversation and story. [Online]. Http://Homepage.Mac.Com/Pelerei/Pelerei/Publications/ Pkm\%20personal\%20assess\%200107.Pdf (Accessed on 29 May, 2010).

Business Wire. 2008. National workplace survey reveals American professionals overwhelmed, headed for "Breaking Point". [Online]. http://findarticles.com/p/articles/mi_m0EIN/is_2008_Feb_26/ai_n24[250[0/. (Accessed on 22 May, 20l0).

Cheong, RKF \& Tsui, E. 2010. The roles and values of personal knowledge management: an exploratory study. Vine, 40 (2): 204 - 227.

Constandse, R. 2007. Time thoughts: resources for personal and career success. [Online]. http://www.timethoughts.com/timemanagement.htm. (Accessed on 22 May, 20l0).

David Skyrme Associates. 2004. Your say: personal knowledge management. Inside Knowledge”, 7 (7). [Online]. http://

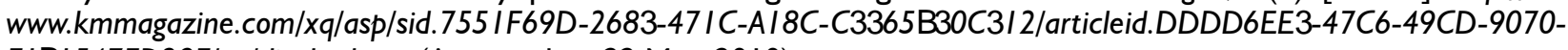
FI I547FD29F/qx/display.htm. (Accessed on 22 May, 2010).

Drucker, PF. 1968. The age of discontinuity: guidelines to our changing society. New York: Harper \& Row.

Drucker, PF. 200I. Management: tasks, responsibilities, practices. Oxford: Butterworth-Heinemann.

Efimova, L. 2006. Understanding personal knowledge management: a weblog case. [Online]. https://doc.telin.nl/dsweb/Get/ Document-44969/pkm_weblogs_final.pdf. (Accessed on 29 May, 2010).

Estes, P. 20 I0. What is time management? [Online]. http://www.wisegeek.com/what-is-time-management.htm. (Accessed on $2 \mathrm{I}$ November, 20I0).

Frand, J \& Hixon, C. 1999. Personal knowledge management: who, what, why, when, where, how? Working paper, UCLA Anderson School of Management. [Online]. http://www.anderson.ucla.edu/faculty/jason.frand/researcher/speeches/PKM.htm. (Accessed on 29 May, 2010). 
Garner, S. 2010. Supporting the personal knowledge management of students with technology. [Online]. http:// proceedings.informingscience.org/InSITE20I0/InSITEI0p2 \7-246Garner764.pdf. (Accessed on 22 May, 20I0)

Google Docs 2010. [Online]. http://docs.google.com. (Accessed on 20 November, 2010).

Gurteen, D. 2009. Personal knowledge management. [Online]. http://www.gurteen.com/gurteen/gurteen.nsf/id/pkm. (Accessed on 20 June, 2010).

Higgison, S. 2004. Your say: Personal knowledge management. InsideKnowledge, 7(7). [Online]. http://www.kmmagazine.com/xq/

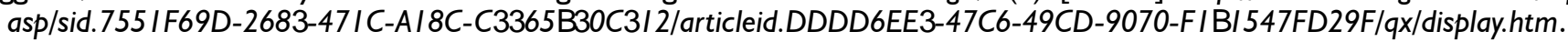
(Accessed on 5 June, 2010).

InsideKnowledge 2004. Your say: Personal knowledge management. InsideKnowledge,7(7). [Online]. http://

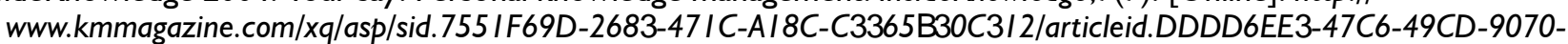
FI $1547 F D 29 F / q x / d i s p l a y . h t m$. (Accessed on 29 May, 2010).

Jefferson, TL. 2006. Taking it personally: personal knowledge management, VINE, 36 (I): 35-7.

Jones, W \& Teevan, J. 2007. Personal information management. University of Seattle, WA: Washington Press.

Jones, R, Corner, J \& Hämäläinen, RP. 2008. Systems intelligence as a lens for managing personal knowledge. [Online]. www.sal.hut.fi/Publications/pdf-files/MJON08.doc. (Accessed on I 3 June, 2010).

Kiessling, TS, Richey, RG, Meng, J \& Dabic, M. 2009. Exploring knowledge management to organizational performance outcomes in a transitional economy. Journal of World [usiness, 44: 421-433.

Lambe, P. 2002. Personal knowledge management: a DIY Guide to knowledge management - Part 2. [Online]. http:// www.greenchameleon.com/thoughtpieces/pkm.pdf. (Accessed on 26 June, 2010).

Mart, VJM \& Enache, M. 2008. Managing personal human capital for professional excellence: an attempt to design a practical methodology, Knowledge Management Research \& Practice, 6 (I): 52-6I.

Martin, J. 2006. Personal knowledge management: the basis of corporate and institutional knowledge management. [Online]. http://www.spottedcowpress.ca/KnowledgeManagement/pdfs/06Martinj.pdf (Accessed on 29 May, 20l0).

Pauleen, D. 2009. Personal knowledge management: putting the 'person' back into the knowledge equation. Online Information Review. 33(2): 22I-224.

Pettenati, MC, Cigognini, ME \& Sorrentin, F. 2007. Methods and tools for developing personal knowledge management skills in the connectivist era. [Online]. http://www.google.co.bw/search?q=Pettenati, + M.C., +Cigognini, + M.E.\&hl=en\&prmd=iv\&ei= yOoETanxMMH $\square$ sgbTIP2HCg\&start = I0\&sa =N (Accessed on I 3 June, 2010).

Polanyi, M. 1958. Personal knowledge: towards a post-critical philosophy. London: Routledge \& Kegan Paul Ltd.

PpcSoft. 20I I. PpcSoft iKnow 2010 for Windows. [Online]. http://www.ppcsoft.com/iknow.asp (Accessed on I8 March, $20 \mathrm{I}$ I).

Pollard, D. 2008. PKM: A bottom-up approach to knowledge management. In Knowledge Management in Practice: Connections and Context, edited by. TK Srikantaiah and MED Koenig, Information Today, pp. 95 - I I 4 [Online]. http://www.gurteen.com/gurteen/ gurteen.nsf/id/kcafe-pollard (Accessed on 29 May, 20l0).

Richardson, D. 200I. The practical reality of knowledge management within development initiatives. KM4 Development, I(2): [Online]. http://www.bellanet.org/files/KM4Dev\%20PDF.pdf (Accessed on I 3 June, 2010).

SaaS. 20I0. [Online]. http://it.toolbox.com/wiki/index.php/SaaS. (Accessed on II December, 20I0).

Verma, S. 2009. Personal knowledge management: a tool to expand knowledge about human cognitive capabilities. IACSIT International Journal of Engineering and Technology, I (5): 435-438. http://www.ijetch.org/papers/8INew.pdf (Accessed on I2 December, 2010).

Volkel, M \& Abecker, A. 2008. Cost-benefit analysis for the design of personal knowledge management systems. International Conference on Enterprise Information Systems. pp. 95-105. [Online]. citeseerx.ist.psu.edu/viewdoc/downloa. (Accessed on I3 June, 2010).

Wales, J. 20I0. Personal knowledge management. [Online]. http://en.wikipedia.org/w/index.php?oldid= $\square / 5507069$ Accessed on 21 November, 20l0).

Wright, K. 2007. Personal Knowledge Management Planning Guide: developing ways to work smarter not harder. [Online]. http://www.knowledgeresources.ca/Knowledge_Resources/PKM_Planning_files/PKM\%20Planning\%20Guide.pdf (Accessed on I3 June, 2010).

ZOHO. 20I0. [Online]. http://www.zoho.com/ (Accessed on 21 November, 20I0).

\section{Further Reading}

Carter, SC. 2010. Procurement skills - how to improve your productivity with a personal knowledge management system. [Online]. http://ezinearticles.com/?Procurement-Skills---How-to-Improve-Your-Productivity-With-a-Personal-KnowledgeManagement-System\&id $=\square 960687$ (Accessed on 21 November, 2010).

Ismail, S \& Ahmad, MS. 20I I. Managing personal knowledge: understanding the knowledge expert. [Online]. http:// ucsi.academia.edu/Shahrinazlsmail/Papers/ $\square / \square 687 /$ Managing_Personal_Knowledge_Understanding_the_Knowledge_Expert (Accessed on 3 March 20II).

Jain, P. 20I0. Perceptions on harmonisation of personal and organisational knowledge: an empirical study of faculty of humanities at the University of Botswana. A paper presented at the 5 th International Conference on Knowledge Management in Asia Pacific (KMAP 2010) 16-I 8 September 2010, Xi'an, in China. ISBN: 978-962-367-707-3.

Knowledge management online. 2009. Planetary knowledge - personal knowledge management in a global knowledge economy. [Online]. http://www.knowledge-management-online.com/personal-knowledge-management.html (Accessed on I 3 June, 2010). 